\title{
Enzymes involved in folate metabolism and its implication for cancer treatment
}

\author{
Sung-Eun Kim ${ }^{\S}$ \\ Department of Food and Nutrition, Sookmyung Women's University, 100 Cheongpa-ro 47-gil, Yongsan-gu, Seoul 04310, Republic of Korea
}

BACKGROUND/OBJECTIVES: Folate plays a critical role in DNA synthesis and methylation. Intracellular folate homeostasis is maintained by the enzymes folylpolyglutamate synthase (FPGS) and $\mathrm{\gamma}$-glutamyl hydrolase (GGH). FPGS adds glutamate residues to folate upon its entry into the cell through a process known as polyglutamylation to enhance folate retention in the cell and to maintain a steady supply of utilizable folate derivatives for folate-dependent enzyme reactions. Thereafter, GGH catalyzes the hydrolysis of polyglutamylated folate into monoglutamylated folate, which can subsequently be exported from the cell. The objective of this review is to summarize the scientific evidence available on the effects of intracellular folate homeostasis-associated enzymes on cancer chemotherapy.

METHODS: This review discusses the effects of FPGS and GGH on chemosensitivity to cancer chemotherapeutic agents such as antifolates, such as methotrexate, and 5-fluorouracil.

RESULTS AND DISCUSSION: Polyglutamylated (anti)folates are better substrates for intracellular folate-dependent enzymes and retained for longer within cells. In addition to polyglutamylation of (anti)folates, FPGS and GGH modulate intracellular folate concentrations, which are an important determinant of chemosensitivity of cancer cells toward chemotherapeutic agents. Therefore, FPGS and GGH affect chemosensitivity to antifolates and 5-fluorouracil by altering intracellular retention status of antifolates and folate cofactors such as 5,10-methylenetetrahydrofolate, subsequently influencing the cytotoxic effects of 5-fluorouracil, respectively. Generally, high FPGS and/or low GGH activity is associated with increased chemosensitivity of cancer cells to methotrexate and 5-fluorouracil, while low FPGS and/or high GGH activity seems to correspond to resistance to these drugs. Further preclinical and clinical studies elucidating the pharmocogenetic ramifications of these enzyme-induced changes are warranted to provide a framework for developing rational, effective, safe, and customized chemotherapeutic practices.

Nutrition Research and Practice 2020;14(2):95-101; https://doi.org/10.4162/nrp.2020.14.2.95; pISSN 1976-1457 elSSN 2005-6168

Keywords: Folate, cancer, chemotherapy, antifolates, 5-fluorouracil

\section{INTRODUCTION}

Folate is a water-soluble B vitamin that acts as an important mediator of one-carbon transfer and plays a crucial role in human health and disease [1]. Naturally occurring folates are present in green leafy vegetables, asparagus, broccoli, legumes, whole grain, and organ meats and are extremely unstable and easily oxidized in low pH conditions. In contrast, folic acid (FA) is the most stable and a fully oxidized monoglutamyl synthetic form of folate that is commonly used in commercial supplements and fortified food products [1]. Ever since the mandate on FA fortification of white wheat flour, cereal, and enriched pastas was passed in 1998, grain products have been used as a major source of folate in the United States and Canada [2]. Folate deficiency is reportedly associated with the development of neural tube defects and congenital disorders, anemia, atherosclerosis, adverse pregnancy outcomes, neuropsychiatric disorders, and cognitive impairments [3]. Accumulating epidemiological evidence suggests an inverse relationship between dietary folate intake or blood folate levels and the risk of multiple malignancies, including lung, oropharyngeal, esophageal, stomach, colorectal, prostate, and breast cancer [3-7]. However, clinical and preclinical studies suggest that excess FA consumption is associated with an increased risk of progression of established precancerous lesions, indicating that folate may play a dual modulatory role in cancer development and progression [5,6,8-10].

A study using the National Health and Nutrition Examination Survey (NHANES) 2003-2006 data $(n=11,462)$ reported that $34.5 \%$ of the population in the United States used dietary supplements containing FA. The use of dietary supplements containing FA was highest in individuals aged 51-71 years, with $5 \%$ of the individuals consuming FA above the tolerable upper intake level (UL) from dietary supplements alone [11]. Another study that used data from the Canadian Community Health Survey 2.2 $(n=34,381)$ revealed that $25 \%$ of the study population

\footnotetext{
This work was supported by Sookmyung Women's University Research Grants (1-1703-2048).

${ }^{\S}$ Corresponding Author: Sung-Eun Kim, Tel. 82-2-2077-7722, Fax. 82-2-710-9479, Email. sekim@sookmyung.ac.kr

Received: January 31, 2020, Revised: February 5, 2020, Accepted: February 13, 2020

This is an Open Access article distributed under the terms of the Creative Commons Attribution Non-Commercial License (http://creativecommons.org/licenses/by-nc/3.0/ which permits unrestricted non-commercial use, distribution, and reproduction in any medium, provided the original work is properly cited.
} 
consumed supplements containing FA, and $9-14 \%$ of individuals aged 14 years or above consuming vitamin/mineral supplements had a consumption above the permissible UL for FA [12]. Furthermore, use of supplements by cancer survivors is relatively common. The previous systematic review reported that $64-81 \%$ of cancer survivors used a vitamin or mineral supplement and $14-32 \%$ of survivors started taking supplements after diagnosis [13]. Several studies on the use of FA supplements have been conducted on colorectal cancer (CRC) survivors. In CRC survivors, the consumption of FA-containing supplements increased from $35.4 \%$ to $55.1 \%$ after diagnosis, while consumption of FA or FA-containing supplements was higher among female survivors [14-16]. However, a growing body of evidence suggests that folate supplementation enhances efficacy of anticancer drugs, such as 5-fluorouracil (5FU), and helps in management of treatment toxicity due to antifolates, whereas increased folate levels may interfere with the efficacy of chemotherapeutic agents and induce drug resistance [17-20]. This review discusses the effects of enzymes associated with maintenance and distribution of intracellular folate on antifolatesand 5FU-based cancer chemotherapy.

\section{Intracellular folate homeostasis}

Monoglutamates are the only form of folate present in circulation, while intracellular folate molecules primarily exist as polyglutamates after cellular uptake by transporters such as reduced folate carrier (RFC), folate receptor, and proton-coupled folate transporter [1]. Upon its entry into the cell, the folate molecules are linked to glutamate residues by the enzyme folylpolyglutamate synthase (FPGS) through a process known as polyglutamylation; this facilitates the retention of folate in the cell and helps maintain a steady supply of utilizable folate derivatives for folate-dependent enzyme reactions. $\gamma$-glutamyl hydrolase (GGH) is an enzyme that catalyzes the hydrolysis of polyglutamylated folate into monoglutamylated folate that is subsequently exported from the cell. Both FPGS and GGH are critical enzymes that function synergistically to maintain intracellular folate concentration and distribution $[1,21]$.

\section{Folate and cancer treatment}

Folate is an essential cofactor for DNA synthesis; therefore, folate depletion and disrupted folate metabolism can reduce the efficacy of DNA synthesis, resulting in inhibition of tumor growth in neoplastic cells; this theory forms the basis for cancer chemotherapy using antifolates and 5FU [22]. Antifolates, such as methotrexate (MTX), used for the treatment of human malignancies and rheumatoid arthritis (RA) are structurally similar to folate and act by binding to or inhibiting folatedependent enzymes [23]. MTX typically acts by inhibiting dihydrofolate reductase and reducing the intracellular folate concentration necessary for thymidylate and purine synthesis, eventually preventing DNA synthesis (Fig. 1). Additionally, MTX polyglutamates can directly inhibit thymidylate synthase (TS) and enzymes involved in de novo purine biosynthesis [24,25]. Similar to folates, polyglutamylated antifolates exhibit better retention in cells, thereby increasing the cytotoxicity of antifolates by increasing the duration of exposure [21,22]. Moreover, polyglutamylated antifolates inhibit their target folate-dependent enzymes involved in thymidylate and purine biosynthesis more efficiently as the polyglutamylated forms exhibit higher affinity for these enzymes compared to the monoglutamated forms $[21,22]$.

$5 \mathrm{FU}$, a prototype of pyrimidine antagonists, is widely used in the treatment of colon and breast cancer [26]. One of the cytotoxic mechanisms adopted by 5FU is the formation of a ternary complex involving 5-fluoro-2-deoxyuridine-5-monophosphate (5FdUMP, a metabolite of 5FU), TS, and 5,10-methylenetetrahydrofolate (5,10-methyleneTHF) [27]. This ternary complex suppresses TS activity with consequent depletion of intracellular thymidylate reserves, resulting in inhibition of DNA synthesis (Fig. 1) [27]. Leucovorin (LV; 5-formylTHF), a precursor of 5,10-methyleneTHF, potentiates 5FU cytotoxicity by stabilizing the inhibitory ternary complex (Fig. 1) [27]. 5,10-methyleneTHF with longer chain polyglutamates exhibit greater potential for the formation and stabilization of the 5,10-methyleneTHFTS-5FdUMP ternary complex than those with shorter chain polyglutamates, suggesting that 5,10-methyleneTHF polyglutamylation may influence 5FU efficacy [28].

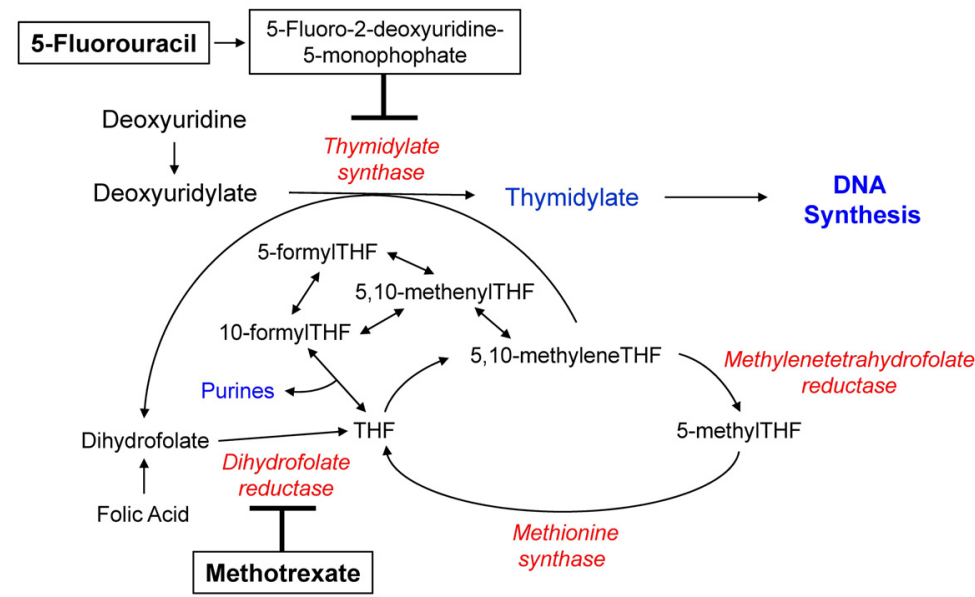

Fig 1. Summary of folate metabolism and targets of methotrexate and 5-fluorouracil. THF: tetrahydrofolate. Adapted and modified with permission from the publisher (Nutrition Reviews ${ }^{(3)}$ 
A growing body of evidence suggests that FPGS and GGH affect chemosensitivity of cancer cells to antifolates and 5FU by altering duration of intracellular retention of antifolates and 5,10-methyleneTHF (a specific target folate cofactor for 5FU), respectively [29,30]. In addition to their implication in polyglutamylation, FPGS and GGH alter the intracellular folate status, which is a critical determinant of chemosensitivity of cancer cells to chemotherapeutic agents designed to interrupt intracellular folate metabolism and DNA synthesis [29-31]. Therefore, FPGS and GGH play a substantial role in the maintenance of intracellular homeostasis of folates and antifolates for optimal folate-dependent one-carbon transfer reactions and antifolateinduced cytotoxic effects.

Folate mediates the transfer of one-carbon units in DNA methylation as well, which might influence chemotherapeutic effects by altering expression of genes involved in drug response $[1,32]$. Given that polyglutamylated folates act as better substrates for enzymes involved in DNA methylation, such as methyleneTHF reductase and methionine synthase, polyglutamylation plays a pivotal role in DNA methylation [21,33] (Fig. 1). Therefore, FPGSand GGH-mediated polyglutamylation-induced changes in DNA methylation might affect chemosensitivity to chemotherapeutic agents.

Effects of folylpolyglutamate synthase on cancer chemotherapy Several studies report the effects of differential FPGS activity and FPGS modulation on drug resistance of and chemosensitivity to antifolates such as MTX and 5FU. Considering that FPGS has a lower affinity for MTX compared to that for folates (dihydrofolate $>$ THF $>$ 5-methylTHF $>$ MTX), the formation of MTX polyglutamates is slower than that of folate polyglutamates. Therefore, reduced FPGS activity would affect folate polyglutamate pools less significantly and critically reduce MTX cytotoxicity [34,35]. In general, high FPGS activity or its upregulation seems to enhance chemosensitivity of cancer cells to MTX and 5FU, whereas low FPGS activity or downregulation appears to correspond to resistance to these drugs. FPGS overexpression was associated with enhanced MTX efficacy in AUXB1 variant hamster cells lacking endogenous FPGS activity [36]. Upregulation of FPGS gene expression increased sensitivity to MTX and other antifolates in 9L rat gliosarcoma cells [37]. On the contrary, FPGS inhibition has been suggested as the mechanism underlying resistance to antifolates such as MTX in human and murine leukemia cells [38-43]. Reduced FPGS activity was associated with resistance to 5FU in CCRF-CEM human acute lymphocytic leukemia (ALL) and HCT8 human colon adenocarcinoma cells [44-46]. Sohn et al. [47] reported that FPGS overexpression increases and FPGS inhibition decreases the chemosensitivity of HCT116 human colon adenocarcinoma cells toward 5FU. The same group of authors highlighted that in MDA-MB-435 human breast adenocarcinoma cells, FPGS overexpression increases chemosensitivity to MTX, while FPGS inhibition reduces 5FU-induced chemosensitivity at supraphysiologial folate medium concentrations [29]. In addition, FPGS modulation affects polyglutamylation of antifolates and specific target folate cofactors (for example, 5,10-methyleneTHF for $5 \mathrm{FU})$, as well as of intracellular folate cofactors, which are critical determinants of antifolate and 5FU cytotoxicity [22,29,47-49].
FPGS plays an important role in cancer cell sensitivity to antifolates and 5FU; therefore, FPGS modulation might be a potential therapeutic target for increasing cancer cell sensitivity to these chemotherapeutic agents.

Altered FPGS expression was reported to be associated with CRC patient outcome. Odin et al. [50] reported that the expression of RFC, FPGS, GGH, and TS increased in CRC tumor biopsies compared to that in the adjacent non-neoplastic mucosa. Moreover, they revealed the association between low expression of RFC and FPGS and the absence of the mRNA splice variant of the putative tumor suppressor gene deleted in colorectal carcinoma (DCC) in normal-appearing mucosa of CRC patients [51]. Although several single-nucleotide polymorphisms (SNPs) have been reported in the FPGS gene, there are a limited number of studies on the functionality or frequencies of these SNPs $[52,53]$. The mutant Cys346Phe FPGS reportedly interferes with L-glutamate or ATP binding, resulting in disruption of FPGS activity [41]. The CC genotype of FPGS rs $1544105 C>T$ was associated with poor response to MTX in patients with RA and pediatric B-cell precursor ALL [54,55]. Furthermore, in lymphoid cells, FPGS expression was epigenetically regulated by chromatin remodeling through interactions between NFY, Sp1, and histone deacetylase (HDAC) factors binding to the FPGS promoter region, resulting in low intracellular accumulation of long-chain MTX polyglutamates [56]. Conversely, HDAC inhibitors increased FPGS expression and long-chain MTX polyglutamate accumulation in childhood ALL cells [57]. In addition, FPGS modulation altered DNA methylation and expression of genes associated with folate biosynthesis and one-carbon metabolism along with increased 5FU efficacy in response to FPGS overexpression $[29,58]$. This result indicates that FPGS-mediated polyglutamylation-induced changes in DNA methylation might influence chemosensitivity to chemotherapeutic agents as well.

\section{Effects of y-glutamyl hydrolase on cancer chemotherapy}

As mentioned previously, both FPGS and GGH are involved in the maintenance of intracellular folate and antifolate homeostasis. GGH was reported to have a higher affinity for longer chain polyglutamates (for example, $\mathrm{Glu}_{4}$ versus $\mathrm{Glu}_{1}$ derivatives, $\mathrm{Km} \mathrm{17-} \mathrm{and} \mathrm{15-fold} \mathrm{lower} \mathrm{for} \mathrm{folate} \mathrm{and} \mathrm{MTX,} \mathrm{respectively)} \mathrm{in}$ HT-1080 human sarcoma cells [59]. The ratio of GGH/FPGS serves as a reliable predictor of the relative concentrations of long-chain MTX polyglutamates in patients with acute leukemia, whereas the ratio of FPGS/GGH was associated with MTX-Glu u $_{4-6}$ accumulation and MTX resistance in childhood leukemia patients [60,61]. A growing body of evidence suggests the association between lower FPGS and/or higher GGH activity and reduced antifolate polyglutamylation, which is related to drug resistance [62-66]. Compared to parental H35 cells, an increase of approximately 7-fold in GGH activity and no change in FPGS activity was observed in $\mathrm{H} 35 \mathrm{D}$ rat hepatoma cells resistant to the antifolate 5,10-dideazatetrahydrofolate (DDATHF) [64]. In this study, two H35 cell lines had nearly equal intracellular folate levels; however, the polyglutamate chains in H35D cells were predominantly composed of $\mathrm{Glu}_{3}$ and $\mathrm{Glu}_{4}$, while those in H35 cells were primarily composed of $\mathrm{Glu}_{5}$ and $\mathrm{Glu}_{6}$ [64]. Moreover, folate and antifolate accumulation was reduced in H35D cells 
along with an increase in GGH activity [66]. Similarly, the resistance in MTX-resistant HT-1080 and DDATHF-resistant CCRF-CEM human leukemia cells was attributed to increased GGH activity [62,63]. In addition, Kim et al. [30] demonstrated that GGH overexpression reduced the chemosensitivity of HCT116 and MDA-MB-435 cells to MTX and 5FU, which was affected by exogenous folate levels.

Conversely, there are several studies that highlight the association between a reduced GGH activity and an increased accumulation of long-chain MTX polyglutamates. A previous study reported that cellular and secreted GGH levels were reduced by $60 \%$ in the presence of insulin in H35 cells [67]. Given that the presence of insulin increased MTX glutamylation by 3-fold in intact H35 cells [68,69], O'Connor et al. [67] suggested that insulin-induced polyglutamylation enhancement might be related to the reduction in GGH levels. This explanation was further validated by a study that indicated an inverse relation between insulin-induced reduction in GGH activity and the changes in intracellular synthesis and accumulation of MTX polyglutamate [70]. An inverse association was observed between GGH activity and the accumulation of total and long-chain $\left(\mathrm{Glu}_{4-7}\right)$ MTX polyglutamates in the blast cells of ALL patients administered a high dose of MTX.

Furthermore, reduction in GGH expression in DLD-1 human colon cancer cells induced by small-interfering RNA (siRNA) increased sensitivity to $5 \mathrm{FU}+\mathrm{LV}$ or only to $5 \mathrm{FU}$, presumably due to improved retention of 5,10-methyleneTHF [31]. In this study, siRNA- induced FPGS downregulation reduced the basal levels of reduced folate, the accumulation and retention of folate in LV-treated DLD-1 cells, and the sensitivity to 5FU+LV. These results suggest that tumors expressing high levels of FPGS and low levels of GGH are likely to be most sensitive to 5FU-induced chemosensitivity in the presence of LV [31]. Another study reported that siRNA-induced GGH inhibition significantly enhanced chemosensitivity of HCT116 and MDA-MB-435 cells to $5 \mathrm{FU}$ and the chemotherapeutic effect was augmented by the increase in exogenous folate levels [30]. In addition, the CpG island methylator phenotype (CIMP)+, accounting for approximately $17 \%$ of CRC cases [71], is associated with low GGH expression and high 5,10-methyleneTHF levels compared to CIMP- tumors, which correspond to positive response of CIMP+ tumors to 5FU $[72,73]$. However, FPGS levels did not differ significantly between CIMP+ and CIMP- tumors [73], suggesting that FPGS might have a lesser impact than GGH on chemosensitivity of CRC to 5FU.

Several SNPs identified in the GGH gene bases have been shown to compromise the promoter as well as the coding regions of the gene [74]. These promoter polymorphisms were associated with increased GGH expression in HepG2 human hepatoma cells. $-401 \mathrm{C}>\mathrm{T}$ and $-124 \mathrm{~T}>\mathrm{G}$ showed enhanced GGH expression in MCF7 human breast cancer cells, suggesting that polymorphisms in the GGH gene promoter may increase GGH expression [74]. Moreover, the GGH-401 T allele frequency varied among ethnic or populations groups in healthy adults-22-36\% in Asian, 31\% in Caucasian, and 14\% in African population groups [75]. In RA patients, patients with the TT genotype of $-401 \mathrm{C}>\mathrm{T}$ were associated with higher GGH activity compared to patients with CC or CT genotypes, indicating that the $\Pi$ genotype might be related to poor response to antifolates [76]. However, in Korean patients with cervical cancer who underwent radical hysterectomy, a poor response to platinum-based neoadjuvant chemotherapy was associated with the CC genotype of $-401 \mathrm{C}>\mathrm{T}$, which might be attributed to the counteractive effects of CC genotypes of XRCC1 A194T and GGH $-401 \mathrm{C}>\mathrm{T}$ in cervical cancer [77]. Furthermore, there was an interethnic difference in the GGH 452 T allelic frequency$14 \%$ in Caucasian, $9-10 \%$ in Asian, and $8 \%$ in African population groups [75]. GGH +452C >T was associated with low GGH activity and high MTX polyglutamate accumulation in ALL patients [78]. In addition to SNPs, epigenetic regulation can modulate GGH activity and MTX polyglutamate accumulation in human leukemia cells. Methylation of two CpG islands (CpG1 and CpG2) in the GGH promoter was associated with reduced GGH mRNA expression/activity and higher accumulation of MTX polyglutamates in human acute leukemia cells, which would suitably explain the better response to antifolates [79,80]. Previous studies that adopted epigenomic and genomic approaches suggested that GGH modulation-induced alterations in concentrations of total intracellular and long-chain polyglutamylated folate affected global and gene-specific DNA methylation and gene expression that was partially associated with 5FU efficacy $[30,81]$. When considered collectively, it appears that identified and characterized GGH SNPs and/or GGH-induced epigenetic changes contribute to functional and pharmacological consequences in cancer cells.

\section{CONCLUSIONS}

Notwithstanding the complexity of FPGS- and GGH-induced changes in folate and antifolate accumulation and metabolism, the potential roles played by genetic variants of these enzymes in antifolate- and 5FU-based cancer chemotherapy warrants further investigation. Elucidating the pharmocogenetic ramifications of these enzyme-induced changes will provide a framework for developing rational, effective, safe, and customized chemotherapeutic practices.

\section{CONFLICT OF INTEREST}

The author declares no potential conflicts of interests.

\section{ORCID}

Sung-Eun Kim: https://orcid.org/0000-0002-1472-2405

\section{ABBREVIATIONS}

ALL, acute lymphocytic leukemia

CIMP, CpG island methylator phenotype

$\mathrm{CRC}$, colorectal cancer

DCC, deleted in colorectal carcinoma

DDATHF, 5,10-dideazatetrahydrofolate

FA, folic acid

FPGS, folylpolyglutamate synthase

5FdUMP, 5-fluoro-2-deoxyuridine-5-monophosphate

5FU, 5-fluorouracil 
GGH, y-glutamyl hydrolase

HDAC, histone deacetylase

LV, leucovorin

MTX, methotrexate

NHANES, National Health and Nutrition Examination Survey

$\mathrm{RA}$, rheumatoid arthritis

RFC, reduced folate carrier

siRNA, small-interfering RNA

SNPs, single-nucleotide polymorphisms

THF, tetrahydrofolate

TS, thymidylate synthase

UL, tolerable upper intake level

\section{REFERENCES}

1. Shane B. Folate chemistry and metabolism. In: Bailey LB, editor. Folate in Health and Disease. Boca Raton (FL): CRC Press; 2010. p.1-24.

2. Gropper SAS, Smith JL, Groff JL. Advanced Nutrition and Human Metabolism. Belmont (CA): Wadsworth/Cengage Learning; 2009.

3. Kim Yl. Role of folate in colon cancer development and progression. J Nutr 2003;133:3731S-3739S.

4. Kim Yl. Folate and carcinogenesis: evidence, mechanisms, and implications. J Nutr Biochem 1999;10:66-88.

5. Kim Yl. Folate and colorectal cancer: an evidence-based critical review. Mol Nutr Food Res 2007;51:267-92.

6. Kim YI. Folic acid supplementation and cancer risk: point. Cancer Epidemiol Biomarkers Prev 2008;17:2220-5.

7. Park YM, Youn J, Cho CH, Kim SH, Lee JE. Circulating folate levels and colorectal adenoma: a case-control study and a meta-analysis. Nutr Res Pract 2017;11:419-29.

8. Figueiredo JC, Grau MV, Haile RW, Sandler RS, Summers RW, Bresalier RS, Burke CA, McKeown-Eyssen GE, Baron JA. Folic acid and risk of prostate cancer: results from a randomized clinical trial. J Natl Cancer Inst 2009;101:432-5.

9. Hirsch S, Sanchez H, Albala C, de la Maza MP, Barrera G, Leiva L, Bunout D. Colon cancer in Chile before and after the start of the flour fortification program with folic acid. Eur J Gastroenterol Hepatol 2009;21:436-9.

10. Mason JB, Dickstein A, Jacques PF, Haggarty P, Selhub J, Dallal G, Rosenberg $\mathrm{IH}$. A temporal association between folic acid fortification and an increase in colorectal cancer rates may be illuminating important biological principles: a hypothesis. Cancer Epidemiol Biomarkers Prev 2007;16:1325-9.

11. Bailey RL, Dodd KW, Gahche JJ, Dwyer JT, McDowell MA, Yetley EA, Sempos CA, Burt VL, Radimer KL, Picciano MF. Total folate and folic acid intake from foods and dietary supplements in the United States: 2003-2006. Am J Clin Nutr 2010;91:231-7.

12. Shakur YA, Tarasuk V, Corey P, O'Connor DL. A comparison of micronutrient inadequacy and risk of high micronutrient intakes among vitamin and mineral supplement users and nonusers in Canada. J Nutr 2012;142:534-40.

13. Velicer $\mathrm{CM}$, Ulrich $\mathrm{CM}$. Vitamin and mineral supplement use among US adults after cancer diagnosis: a systematic review. J Clin Oncol 2008;26:665-73.

14. Holmes RS, Zheng Y, Baron JA, Li L, McKeown-Eyssen G, Newcomb PA, Stern MC, Haile RW, Grady WM, Potter JD, Le Marchand L, Campbell PT, Figueiredo JC, Limburg PJ, Jenkins MA, Hopper JL,
Ulrich $\mathrm{CM}$; Colon Cancer Family Registry. Use of folic acid-containing supplements after a diagnosis of colorectal cancer in the Colon Cancer Family Registry. Cancer Epidemiol Biomarkers Prev 2010;19: 2023-34.

15. Satia JA, Campbell MK, Galanko JA, James A, Carr C, Sandler RS. Longitudinal changes in lifestyle behaviors and health status in colon cancer survivors. Cancer Epidemiol Biomarkers Prev 2004;13: 1022-31.

16. Sandler RS, Halabi S, Kaplan EB, Baron JA, Paskett E, Petrelli NJ. Use of vitamins, minerals, and nutritional supplements by participants in a chemoprevention trial. Cancer 2001;91:1040-5.

17. Assaraf YG. The role of multidrug resistance efflux transporters in antifolate resistance and folate homeostasis. Drug Resist Updat 2006;9:227-46.

18. Hooijberg JH, de Vries NA, Kaspers GJ, Pieters R, Jansen G, Peters GJ. Multidrug resistance proteins and folate supplementation: therapeutic implications for antifolates and other classes of drugs in cancer treatment. Cancer Chemother Pharmacol 2006;58:1-12.

19. Porcelli L, Assaraf YG, Azzariti A, Paradiso A, Jansen G, Peters GJ. The impact of folate status on the efficacy of colorectal cancer treatment. Curr Drug Metab 2011;12:975-84.

20. Assaraf YG. Molecular basis of antifolate resistance. Cancer Metastasis Rev 2007;26:153-81.

21. Moran RG. Roles of folylpoly-gamma-glutamate synthetase in therapeutics with tetrahydrofolate antimetabolites: an overview. Semin Oncol 1999;26:24-32.

22. Kamen B. Folate and antifolate pharmacology. Semin Oncol 1997;24:S18-30-S18-39.

23. Zhao R, Goldman ID. Resistance to antifolates. Oncogene 2003;22: 7431-57.

24. Calvert $\mathrm{H}$. An overview of folate metabolism: features relevant to the action and toxicities of antifolate anticancer agents. Semin Oncol 1999;26:3-10.

25. Kremer JM. Toward a better understanding of methotrexate. Arthritis Rheum 2004;50:1370-82.

26. Grem JL. 5-Fluorouracil: forty-plus and still ticking. A review of its preclinical and clinical development. Invest New Drugs 2000;18: 299-313.

27. Longley DB, Harkin DP, Johnston PG. 5-fluorouracil: mechanisms of action and clinical strategies. Nat Rev Cancer 2003;3:330-8.

28. Radparvar S, Houghton PJ, Houghton JA. Effect of polyglutamylation of 5,10-methylenetetrahydrofolate on the binding of 5-fluoro-2'-deoxyuridylate to thymidylate synthase purified from a human colon adenocarcinoma xenograft. Biochem Pharmacol 1989;38:335-42.

29. Cho RC, Cole PD, Sohn KJ, Gaisano G, Croxford R, Kamen BA, Kim YI. Effects of folate and folylpolyglutamyl synthase modulation on chemosensitivity of breast cancer cells. Mol Cancer Ther 2007;6: 2909-20.

30. Kim SE, Cole PD, Cho RC, Ly A, Ishiguro L, Sohn KJ, Croxford R, Kamen BA, Kim YI. $\gamma$-Glutamyl hydrolase modulation and folate influence chemosensitivity of cancer cells to 5-fluorouracil and methotrexate. Br J Cancer 2013;109:2175-88.

31. Sakamoto E, Tsukioka $S$, Oie $S$, Kobunai T, Tsujimoto $H$, Sakamoto K, Okayama $\mathrm{Y}$, Sugimoto $\mathrm{Y}$, Oka T, Fukushima M, Oka T. Folylpolyglutamate synthase and gamma-glutamyl hydrolase regulate leucovorin-enhanced 5-fluorouracil anticancer activity. Biochem Biophys Res Commun 2008;365:801-7. 
32. Sharma S, Kelly TK, Jones PA. Epigenetics in cancer. Carcinogenesis 2010;31:27-36.

33. McGuire JJ, Bertino JR. Enzymatic synthesis and function of folylpolyglutamates. Mol Cell Biochem 1981;38:19-48.

34. Cichowicz DJ, Shane B. Mammalian folylpoly-gamma-glutamate synthetase. 2. Substrate specificity and kinetic properties. Biochemistry 1987;26:513-21.

35. Cook JD, Cichowicz DJ, George S, Lawler A, Shane B. Mammalian folylpoly-gamma-glutamate synthetase. 4 . In vitro and in vivo metabolism of folates and analogues and regulation of folate homeostasis. Biochemistry 1987;26:530-9.

36. Kim JS, Lowe KE, Shane B. Regulation of folate and one-carbon metabolism in mammalian cells. IV. Role of folylpoly-gammaglutamate synthetase in methotrexate metabolism and cytotoxicity. J Biol Chem 1993;268:21680-5.

37. Aghi M, Kramm CM, Breakefield XO. Folylpolyglutamyl synthetase gene transfer and glioma antifolate sensitivity in culture and in vivo. J Natl Cancer Inst 1999;91:1233-41.

38. Pizzorno G, Mini E, Coronnello M, McGuire JJ, Moroson BA, Cashmore AR, Dreyer RN, Lin JT, Mazzei T, Periti P, Berlino JR. Impaired polyglutamylation of methotrexate as a cause of resistance in CCRF-CEM cells after short-term, high-dose treatment with this drug. Cancer Res 1988;48:2149-55.

39. McCloskey DE, McGuire JJ, Russell CA, Rowan BG, Bertino JR, Pizzorno G, Mini E. Decreased folylpolyglutamate synthetase activity as a mechanism of methotrexate resistance in CCRF-CEM human leukemia sublines. J Biol Chem 1991;266:6181-7.

40. Mauritz R, Peters GJ, Priest DG, Assaraf YG, Drori S, Kathmann I, Noordhuis P, Bunni MA, Rosowsky A, Schornagel JH, Pinedo HM, Jansen G. Multiple mechanisms of resistance to methotrexate and novel antifolates in human CCRF-CEM leukemia cells and their implications for folate homeostasis. Biochem Pharmacol 2002;63: 105-15.

41. Liani E, Rothem L, Bunni MA, Smith CA, Jansen G, Assaraf YG. Loss of folylpoly-gamma-glutamate synthetase activity is a dominant mechanism of resistance to polyglutamylation-dependent novel antifolates in multiple human leukemia sublines. Int J Cancer 2003;103:587-99.

42. Zhao R, Titus S, Gao F, Moran RG, Goldman ID. Molecular analysis of murine leukemia cell lines resistant to 5, 10-dideazatetrahydrofolate identifies several amino acids critical to the function of folylpolyglutamate synthetase. J Biol Chem 2000;275:26599-606.

43. Roy K, Egan MG, Sirlin S, Sirotnak FM. Posttranscriptionally mediated decreases in folylpolyglutamate synthetase gene expression in some folate analogue-resistant variants of the L1210 cell. Evidence for an altered cognate mRNA in the variants affecting the rate of de novo synthesis of the enzyme. J Biol Chem 1997;272:6903-8.

44. Romanini A, Lin JT, Niedzwiecki D, Bunni M, Priest DG, Bertino JR Role of folylpolyglutamates in biochemical modulation of fluoropyrimidines by leucovorin. Cancer Res 1991;51:789-93.

45. Wang FS, Aschele C, Sobrero A, Chang YM, Bertino JR. Decreased folylpolyglutamate synthetase expression: a novel mechanism of fluorouracil resistance. Cancer Res 1993;53:3677-80.

46. Chéradame $S$, Etienne MC, Chazal $M$, Guillot $T$, Fischel JL, Formento $P$, Milano $G$. Relevance of tumoral folylpolyglutamate synthetase and reduced folates for optimal 5-fluorouracil efficacy: experimental data. Eur J Cancer 1997;33:950-9.

47. Sohn KJ, Smirnakis F, Moskovitz DN, Novakovic $P$, Yates Z, Lucock
M, Croxford R, Kim YI. Effects of folylpolyglutamate synthetase modulation on chemosensitivity of colon cancer cells to 5-fluorouracil and methotrexate. Gut 2004;53:1825-31.

48. Backus $H H$, Pinedo HM, Wouters $D$, Padrón JM, Molders N, van Der Wilt $\mathrm{CL}$, van Groeningen $\mathrm{CJ}$, Jansen $\mathrm{G}$, Peters GJ. Folate depletion increases sensitivity of solid tumor cell lines to 5-fluorouracil and antifolates. Int J Cancer 2000;87:771-8.

49. Zhao R, Gao F, Goldman ID. Marked suppression of the activity of some, but not all, antifolate compounds by augmentation of folate cofactor pools within tumor cells. Biochem Pharmacol 2001;61: 857-65.

50. Odin E, Wettergren Y, Nilsson S, Willén R, Carlsson G, Spears CP, Larsson L, Gustavsson B. Altered gene expression of folate enzymes in adjacent mucosa is associated with outcome of colorectal cancer patients. Clin Cancer Res 2003;9:6012-9.

51. Wettergren Y, Odin E, Nilsson S, Willen R, Carlsson G, Gustavsson B. Low expression of reduced folate carrier-1 and folylpolyglutamate synthase correlates with lack of a deleted in colorectal carcinoma mRNA splice variant in normal-appearing mucosa of colorectal carcinoma patients. Cancer Detect Prev 2005;29:348-55.

52. Oppeneer SJ, Ross JA, Koh WP, Yuan JM, Robien K. Genetic variation in folylpolyglutamate synthase and gamma-glutamyl hydrolase and plasma homocysteine levels in the Singapore Chinese Health Study. Mol Genet Metab 2012;105:73-8.

53. van der Straaten RJ, Wessels JA, de Vries-Bouwstra JK, GoekoopRuiterman YP, Allaart CF, Bogaartz J, Tiller M, Huizinga TW, Guchelaar HJ. Exploratory analysis of four polymorphisms in human GGH and FPGS genes and their effect in methotrexate-treated rheumatoid arthritis patients. Pharmacogenomics 2007;8:141-50.

54. Liu SG, Gao C, Zhang RD, Jiao Y, Cui L, Li WJ, Chen ZP, Wu MY, Zheng HY, Zhao XX, Yue ZX, Li ZG. FPGS rs1544105 polymorphism is associated with treatment outcome in pediatric B-cell precursor acute lymphoblastic leukemia. Cancer Cell Int 2013;13:107.

55. Sharma S, Das M, Kumar A, Marwaha V, Shankar S, Singh P, Raghu P, Aneja R, Grover R, Arya V, Dhir V, Gupta R, Kumar U, Juyal RC, $K$ TB. Purine biosynthetic pathway genes and methotrexate response in rheumatoid arthritis patients among north Indians. Pharmacogenet Genomics 2009;19:823-8.

56. Leclerc GJ, Sanderson C, Hunger S, Devidas M, Barredo JC. Folylpolyglutamate synthetase gene transcription is regulated by a multiprotein complex that binds the TEL-AML1 fusion in acute lymphoblastic leukemia. Leuk Res 2010;34:1601-9.

57. Leclerc GJ, Mou C, Leclerc GM, Mian AM, Barredo JC. Histone deacetylase inhibitors induce FPGS mRNA expression and intracellular accumulation of long-chain methotrexate polyglutamates in childhood acute lymphoblastic leukemia: implications for combination therapy. Leukemia 2010;24:552-62.

58. Kim SE, Hinoue T, Kim MS, Sohn KJ, Cho RC, Weisenberger DJ, Laird PW, Kim YI. Effects of folylpolyglutamate synthase modulation on global and gene-specific DNA methylation and gene expression in human colon and breast cancer cells. J Nutr Biochem 2016;29:27-35.

59. Waltham MC, Li WW, Gritsman H, Tong WP, Bertino JR. gammaGlutamyl hydrolase from human sarcoma HT-1080 cells: characterization and inhibition by glutamine antagonists. Mol Pharmacol 1997;51:825-32.

60. Longo GS, Gorlick R, Tong WP, Ercikan E, Bertino JR. Disparate affinities of antifolates for folylpolyglutamate synthetase from human leukemia cells. Blood 1997;90:1241-5. 
61. Rots MG, Pieters R, Peters GJ, Noordhuis $P$, van Zantwijk $C H$, Kaspers GJ, Hählen K, Creutzig U, Veerman AJ, Jansen G. Role of folylpolyglutamate synthetase and folylpolyglutamate hydrolase in methotrexate accumulation and polyglutamylation in childhood leukemia. Blood 1999;93:1677-83.

62. Li WW, Waltham M, Tong W, Schweitzer BI, Bertino JR. Increased activity of gamma-glutamyl hydrolase in human sarcoma cell lines: a novel mechanism of intrinsic resistance to methotrexate (MTX). Adv Exp Med Biol 1993;338:635-8.

63. Pizzorno G, Moroson BA, Cashmore AR, Russello O, Mayer JR, Galivan J, Bunni MA, Priest DG, Beardsley GP. Multifactorial resistance to 5,10-dideazatetrahydrofolic acid in cell lines derived from human lymphoblastic leukemia CCRF-CEM. Cancer Res 1995;55:566-73.

64. Rhee MS, Wang Y, Nair MG, Galivan J. Acquisition of resistance to antifolates caused by enhanced gamma-glutamyl hydrolase activity. Cancer Res 1993;53:2227-30.

65. Schneider E, Ryan TJ. Gamma-glutamyl hydrolase and drug resistance. Clin Chim Acta 2006;374:25-32.

66. Yao R, Rhee MS, Galivan J. Effects of gamma-glutamyl hydrolase on folyl and antifolylpolyglutamates in cultured H35 hepatoma cells. Mol Pharmacol 1995;48:505-11.

67. O'Connor BM, Rotundo RF, Nimec Z, McGuire JJ, Galivan J. Secretion of gamma-glutamyl hydrolase in vitro. Cancer Res 1991;51:3874-81.

68. Nimec Z, Galivan J. Regulatory aspects of the glutamylation of methotrexate in cultured hepatoma cells. Arch Biochem Biophys 1983;226:671-80.

69. Galivan J. Hormonal alteration of methotrexate and folate polyglutamate formation in cultured hepatoma cells. Arch Biochem Biophys 1984;230:355-62.

70. Galivan J, Rhee MS. Insulin-dependent suppression in glutamyl hydrolase activity and elevated cellular methotrexate polyglutamates. Biochem Pharmacol 1995;50:1659-63.

71. Samowitz WS, Albertsen H, Herrick J, Levin TR, Sweeney C, Murtaugh MA, Wolff RK, Slattery ML. Evaluation of a large, population-based sample supports a CpG island methylator phenotype in colon cancer. Gastroenterology 2005;129:837-45.

72. lacopetta B, Kawakami K, Watanabe T. Predicting clinical outcome of 5-fluorouracil-based chemotherapy for colon cancer patients: is the $\mathrm{CpG}$ island methylator phenotype the 5 -fluorouracil-responsive subgroup? Int J Clin Oncol 2008;13:498-503.
73. Kawakami K, Ooyama A, Ruszkiewicz A, Jin M, Watanabe G, Moore J, Oka T, lacopetta B, Minamoto T. Low expression of gammaglutamyl hydrolase mRNA in primary colorectal cancer with the CpG island methylator phenotype. Br J Cancer 2008;98:1555-61.

74. Chave KJ, Ryan TJ, Chmura SE, Galivan J. Identification of single nucleotide polymorphisms in the human gamma-glutamyl hydrolase gene and characterization of promoter polymorphisms. Gene 2003;319:167-75.

75. Hashiguchi M, Shimizu M, Hakamata J, Tsuru T, Tanaka T, Suzaki M, Miyawaki K, Chiyoda T, Takeuchi O, Hiratsuka J, Irie S, Maruyama J, Mochizuki M. Genetic polymorphisms of enzyme proteins and transporters related to methotrexate response and pharmacokinetics in a Japanese population. J Pharm Health Care Sci 2016;2:35

76. Dervieux T, Kremer J, Lein DO, Capps R, Barham R, Meyer G, Smith K, Caldwell J, Furst DE. Contribution of common polymorphisms in reduced folate carrier and gamma-glutamylhydrolase to methotrexate polyglutamate levels in patients with rheumatoid arthritis. Pharmacogenetics 2004;14:733-9.

77. Kim K, Kang SB, Chung HH, Kim JW, Park NH, Song YS. XRCC1 Arginine194Tryptophan and GGH-401Cytosine/Thymine polymorphisms are associated with response to platinum-based neoadjuvant chemotherapy in cervical cancer. Gynecol Oncol 2008;111:509-15.

78. Cheng Q, Wu B, Kager L, Panetta JC, Zheng J, Pui CH, Relling MV, Evans WE. A substrate specific functional polymorphism of human gamma-glutamyl hydrolase alters catalytic activity and methotrexate polyglutamate accumulation in acute lymphoblastic leukaemia cells. Pharmacogenetics 2004;14:557-67.

79. Cheng Q, Cheng C, Crews KR, Ribeiro RC, Pui CH, Relling MV, Evans WE. Epigenetic regulation of human gamma-glutamyl hydrolase activity in acute lymphoblastic leukemia cells. Am J Hum Genet 2006;79:264-74.

80. Li Y, Liu S, Wang H, Mai H, Yuan X, Li C, Chen X, Wen F. Methylation level of $\mathrm{CpG}$ islands in GGH gene promoter in pediatric acute leukemia. PLoS One 2017;12:e0173472.

81. Kim SE, Hinoue T, Kim MS, Sohn K, Cho RC, Cole PD, Weisenberger DJ, Laird PW, Kim YI. $\gamma$-Glutamyl hydrolase modulation significantly influences global and gene-specific DNA methylation and gene expression in human colon and breast cancer cells. Genes Nutr 2015;10:444. 